\title{
Medical Physicist
}

National Cancer Institute

\section{Source}

National Cancer Institute. Medical Physicist. NCI Thesaurus. Code C51842.

A healthcare professional or scientist with knowledge and competence in health physics including but not limited to nuclear medicine, radiotherapy, radiology and various aspects of physiological monitoring and investigation. 